\title{
From the Editor - A New Editorial Board and a New Approach
}

\author{
Willem J. Remme
}

Published online: 3 March 2007

(C) Springer Science + Business Media, LLC 2007

In January 2004, after my first 3 years as Editor-in-Chief of Cardiovascular Drugs and Therapy (CDT), I wrote in the Editor's page, that these first years had been good for the journal and that I looked forward to the years to come.

A second 3-year period has passed - and the question is what have we achieved?

Is there still a reason to be content?

I believe, there is. We have received a steadily rising number of articles, and with that a steadily increase in critical appreciation of quality and suitability for publication. As a consequence, and in order to stay within the limits of available pages in each issue, rejection rate has increased, However, in parallel, so did our citation index.

Another reason to be content regards the speed of the reviewing process. This has considerably shortened compared to the previous 3 years, partly due to few reviewer refusals, a fast return of reviews, and the easiness of the online review system with our new Editorial Manager System. The average review time in 2005 was 18 days.

Moreover, in the past years, CDT has become available on-line and is often visited with a very satisfying number of full text articles viewed. This is particularly true for the new Online First, where articles become available in PDF format the moment they are accepted, well before publication in the regular paper issue of the journal.

That CDT is doing well has many reasons. The input and support of the Editorial Board, in particular that of the Associate and Section Editors, is a very important one, and I am very grateful for their help.

W. J. Remme $(\bowtie)$

Sticares Cardiovascular Research Institute, Oever 1-5, 3161GR Rhoon, The Netherlands

e-mail: w.j.remme@sticares.org
Moreover, as mentioned above, I cannot complain about reviewer support. I have been always happily surprised by the positive responses to our request to review and I want to thank again all those who reviewed in the last 3 years.

Also, I am much obliged to all who accepted to write editorials. These have undoubtedly contributed much to the standing of CDT.

One person deserves to be mentioned by name and that is my excellent Editorial Assistant Noor van Dam, who is really the central and most important person in our Editorial Office, and without whom I would be rather helpless.

\section{A new board and a new approach}

The overriding aim of an Editorial Board and its Editorin-Chief is to improve the quality and standing of the journal at hand. And so it is with CDT.

The Editorial Board has decided to make certain changes in the direction of the Journal. CDT is doing well with a steadily rising citation index. Still, this could be much improved if certain "niche" roles could be found for CDT in the coming years.

Currently, its aim is very broad, and we consider that if the journal were to be recognised by its focus on translational research in specific areas in addition to review and teaching articles pertinent to these areas, that this will help to improve its impact further.

Whereas we will continue with the current lay-out, which I believe works well, i.e. the 4 sections: Basic Pharmacology, Clinical Pharmacology and Drug Studies, Clinical Trials, and Pharmaco-economics and-epidemiology, new sections pertaining to the changes mentioned above will be added. 
Furthermore, a new sub-section on device therapy will be included. Devices have become progressively important in the management of various cardiovascular disease areas; there is in many ways an interaction with pharmacological therapy and it is therefore inappropriate and unwise to exclude them in a journal devoted to cardiovascular disease management and to focus only on drugs.

To ensure optimal handling of these new developments, both the structure and composition of the Editorial Board has been drastically changed.

First, a larger core group of Associate and Section Editors was assembled with the aim of covering the most important cardiovascular disease areas for CDT, global representation and to ensure a high degree of expertise in the day to day management of the journal. I am happy to say that all Associate and Section Editors have enthusiastically responded to my request to function in their respective positions. Their input will be of crucial importance for the success of CDT and I look forward to working with them.

Second, several Board members who have held key positions in the Board for many years will remain as Senior Advisory Editors. Their knowledge of Board matters and experience cannot be missed. Their advice on matters relating to direction and content of the journal will regularly be sought.

Third, it is natural that after several years on the Editorial Board some members will stand down. I take this opportunity to thank them for their support of the journal.

One person who I cannot thank anymore, but who has been of great value and inspiration for the journal and the ISCP, and who was a personal friend, is Ariel Reyes, who tragically died suddenly in August 2006. An obituary written by one of his closest friend can be found in this issue of CDT.

Fourth, many new Board members have joined, all of whom have shown a significant interest in and affiliation with the journal and were selected for their expertise in a specific cardiovascular pharmacological or clinical area. It is with much pleasure that I welcome them. I am certain that their contribution as Editorial Board members will further improve the journal.

While the years 2001-2003 signalled a good start and 2004-2006 showed a steady improvement, I am confident that this tendency will continue, but at a faster speed.

I look forward to even better years to come. 